when the counter moves from placenta to uterine muscle only.

\section{Summary and Conclusions}

The various methods of localization of the placenta have been briefly reviewed.

A method using radio-active sodium has been described.

The results obtained in 255 cases have been presented.

It is concluded that this method is a useful adjunct to the older radiological methods of diagnosis of placenta praevia, and that it is of value in enabling samples of maternal placental blood to be obtained.

\section{BIBLIOGRAPHY}

BURCH, C., REASER, P., and CRONVICH, J. (1947), f. Lab clin. Med., 32, 1 169.

BURKE, F. J. (1935), F. Obst. Gynae. Brit. Emp., 42, 1096.

DIPPEL, A. L., and BROWN, W. H. (1940), Amer. F. Obst. Gynec. 40, 986.

ERHARDT, K. (1932), Kin. Wschr., III, 332, 20 Feb.

LERICHE, R., BEACONSFIELD, P., and BOELY, C. (1952), Surg. Obstet. Gynec., 94, I, 83.

MARINELLI, L. D., QUIMBY, E. H., and HINE, G. J. (1948), Amer. . Roentgenol., 59, 260 .

Med. Res. Counc. (1949), Introductory manual on the control of health hazards from radioactive materials, Issue 2. H.M.S.O., London.

MENEES, T. O., MILLER, J. D., and HOLLY, L. E. (1930), Amer. F. Obstet. Gynec., 24, 363.

MOIR, J. CHASSAR (1944), Amer. F. Obstet. Gynec., 47, 198.

OLSSON, O. (I94I), Acta Rádiol., 22, 279.

REID, F. (1949), Brit. F. Radiol., 22, 557.

SNOW, W., and PWELL, C. B. (1934), Amer. F. Roentgenol., 31, 37. UDE, W. H., and.URNER, J. H. (1938), Amer. F. Roentgenol., 40, 37.

\title{
$\longrightarrow$ \\ THE RADIOLOGICAL LOCALIZATION OF THE PLACENTA
}

\author{
By Frank ReID, M.D.(Leeds), D.M.R.D. \\ Consultant Radiologist, Harrogate and Ripon Group os Hospitals
}

During the latter half of pregnancy plain films of the abdomen show the foetus surrounded by a homogeneous soft tissue shadow which represents uterine muscle, placenta and liquor amnii; the radiographic density of these tissues being identical, special methods have been developed to determine the situation of the placenta.

\section{Methods Employed}

\section{Amniography}

The first attempt to localize the placenta radiographically was made by Menees, Miller and Holly in 1930. They found that the injection of strontium iodide solution through the abdominal wall into the uterine cavity increased the radiographic density of the liquor and revealed the placenta as a crescentic thickening of lesser density on the uterine wall.

Reports of foetal death following the use of strontium led to a search for a less toxic contrast medium; Uroselectan B was used in Io patients by Kerr and Mackey (1933) and by Burke (1935) in 75 patients; no ill effects were observed in either mother or baby, although in many cases labour commenced within a short time of injection.

Insertion of the needle through the abdominal wall is a further source of danger, damage to the placenta, cord or foetus having been reported in some cases.

\section{Intravenous Placentography}

In animal experiments Ehrhardt (1932) and Katsuya (1932) were able to differentiate the placenta from the surrounding tissues following the intravenous injection of thorium dioxide, a radio-opaque substance which is taken up by the placental reticulo-endothelial cells. Unfortunately, thorium is a radioactive substance and is generally considered too dangerous to use as a contrast medium.

In 1939, Ehrhardt was able to identify the placenta in animals as an-opaque shadow following the intravenous injection of the phenyl and ethyl esters of tri-iodo-stearic acid. Olsson (I94I) employed the same contrast medium in human hepato-lienography (for which it was originally intended), but considered it to be unsafe owing to the dangerous reactions which occurred in some of his patients. 


\section{Arteriography}

Although translumbar aortography was first described over 20 years ago, it has only recently become a generally accepted procedure. According to Sante (195I) pools of radio-opaque medium accumulate in the sinusoids of the placenta and reveal its situation.

\section{Soft Tissue Radiography}

In 1934, Snow and Powell described a soft tissue shadow in a lateral view of the abdomen which they believed to represent the placenta and which had a maximum width of $7 \mathrm{~cm}$. Amongst the many papers written in support are those of Dippel and Brown (1940), Buxton, Hunt and Potter (1942), Stander (1942), Manges Smith (1943) and Bishop (1945). Dippel and Brown further stated that a placental shadow which is mostly or entirely below the level of the mother's umbilicus is reliable evidence of placenta praevia.

\section{Tomography}

Lloyd and Samuel (1941) used this procedure in five cases and found evidence of placenta praevia in three; this diagnosis was subsequently confirmed clinically in all three patients.

\section{6. (a) Cystography}

This method was originated by Ude, Weum and Urner (1934), who injected contrast medium through the urethra in order to reveal the soft tissue space separating the fundus of the bladder from the foetal head; this, they considered, should not exceed $\mathrm{I} \mathrm{cm}$. in depth in normal cases.

\section{6. (b) Air Inflation of the Rectum}

Diagnostic errors in cases of posterior placenta, apparently due to the use of cystography alone, led Sohne (1942) to devise a more embracing procedure. Using air as a contrast medium, he injected 100 c.c. into the bladder and 150 to 200 c.c. into the rectum. Lateral films were taken and the space separating the foetal head from both bladder and rectum was estimated; the normal range in either instance was found to lie between 0.8 and $2.1 \mathrm{~cm}$.

\section{Displacement Method}

Stating that the foetal head should normally lie in the mid-coronal and mid-sagittal planes of the inlet when the patient is standing upright, Golden and Ball (I94I) went on to say that displacement of the head from either plane by a third or more of its diameter was an indication of placenta praevia. They considered that their method was applicable in vertex presentations only and that other causes of displacement such as loaded rec $\frac{2}{z}$ tum, distended bladder or pelvic tumour had to be excluded.

Brailsford (1947) published postero-anterio and lateral radiographs, taken with the patient? standing, which showed a wide separation of the foetal head from the promontory; the films had. been sent to him by Dr. F. H. Kemp to show how radiography in the erect position without the use of contrast media might reveal obstruction of thछ pelvic brim due to placenta praevia, provided thequestion of distended bladder or other spaceoccupying mass could be excluded.

In neither of these publications was there any mention of the subsequent history of patients with radiographic evidence of placenta praevia

\section{The Radiographic Appearances of the Normally Situated Placenta}

The placenta is of the same radiographic density and cannot therefore be differentiated from the sur-o rounding uterine muscle and liquor amnii; never-? theless, in most cases a crescentic expansion of

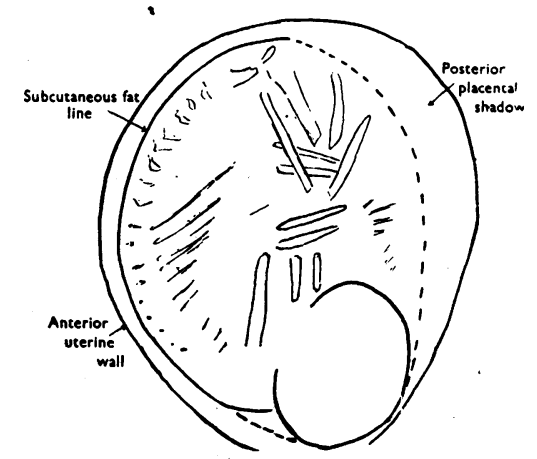

FIG. I.-Radiographic interpretation. Normal posterio placental shadow.

the anterior or posterior wall of the uterus can be demonstrated, which has proved in practices to be reliable evidence of its situation. Implanta tion being nearly always anterior or posterior a lateral radiograph of the abdomen is require of to show this so-called placental shadow.

Interpretation of the lateral radiograph is explained diagrammatically in Fig. I. An in terrupted line encloses the foetus and delineates a peripheral soft tissue shadow of fairly uniform width anteriorly but which expands into the shape of a crescent on the posterior wall. The latter is a composite shadow which compriseso uterine muscle, placenta and liquor amnii; i $\overrightarrow{0}$ is usually some 4 to $7 \mathrm{~cm}$. in depth at the centre and about 20 to $25 \mathrm{~cm}$. long; at either end ip 
merges-into a fairly uniform band between $I$ and $I_{2}^{1} \mathrm{~cm}$. wide, which represents muscle and liquor only. Correcting for radiographic magnification, these figures become 3 to $5 \frac{1}{2} \mathrm{~cm}$., 15 to $20 \mathrm{~cm}$. and 0.8 to $1.2 \mathrm{~cm}$., respectively, the average of each range being $4 \frac{1}{4} \mathrm{~cm}$., $17 \frac{1}{2} \mathrm{~cm}$. and $1 \mathrm{~cm}$. But the depth of the placental shadow is partly due to uterine muscle and liquor, the combined contribution of which should be approximately equal to the depth of shadow on the opposite wall; hence the average cross-section of placenta projected in lateral radiographs is approximately $17 \frac{1}{2}$ $\mathrm{cm}$. long and $3 \frac{1}{4} \mathrm{~cm} .\left(4 \frac{1}{4}-\mathrm{I} \mathrm{cm}\right.$.) in depth at the centre, dimensions which are not far removed from those quoted by standard textbooks.

Variations in the shadow due to the size of the placenta would be expected, but this is not the only factor concerned: its maximum thickness will not always be projected by the $\mathrm{X}$-ray beam, other variables being the width of the uterine muscle and the amount of liquor around the foetus. Fig. 2 shows how asymmetrical implantation, or obliquity of the uterus, may cause projection of the tapering periphery of the placenta and, in extreme cases, how most of the placenta may be on the posterior or anterior wall without any part being in profile to the lateral X-ray beam.

\section{Radiography in Erect Position}

\section{(a) Anterior and Posterior Implantation}

The dimensions of the uterine soft tissue shadows given above were obtained from films taken with the patient lying on her side. But when radiography is performed in the erect posture the anterior placental shadow rarely exceeds 4 or $5 \mathrm{~cm}$. in depth, the reduced figure being almost certainly due to the altered distribution of the liquor which occurs as the foetus sinks on to the inclined anterior uterine wall (Fig. 3).

On the other hand, the average depth of the posterior placental shadow in the erect position is appreciably greater than the average measurement found in radiographs taken with the patient lying down. The explanation for this is probably as follows: when the mother lies on her side the foetus gravitates towards the lower lateral uterine wall, the depth of fluid anteriorly and posteriorly tending to be approximately equal, but when she rises to her feet, the foetus moves and sinks on to the anterior uterine wall, displacing liquor which becomes available to increase the depth of fluid posteriorly.

Occasionally a lateral radiograph shows an equally acceptable placental shadow on both anterior and posterior walls. Nevertheless, provided the film was taken in the erect position, it is safe to assume-with rare exceptions-that im-

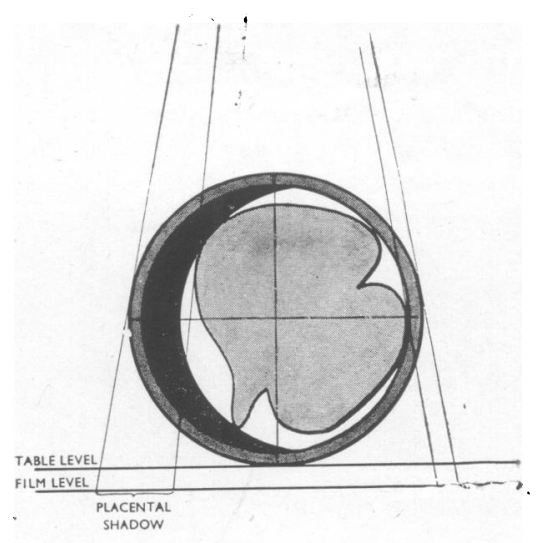

FIG. 2a

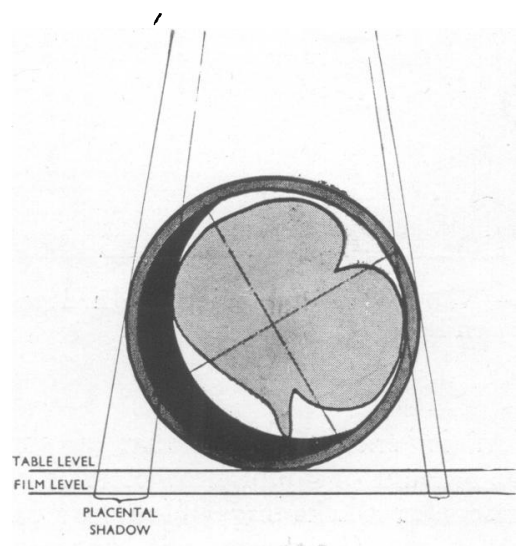

FIG. 2b

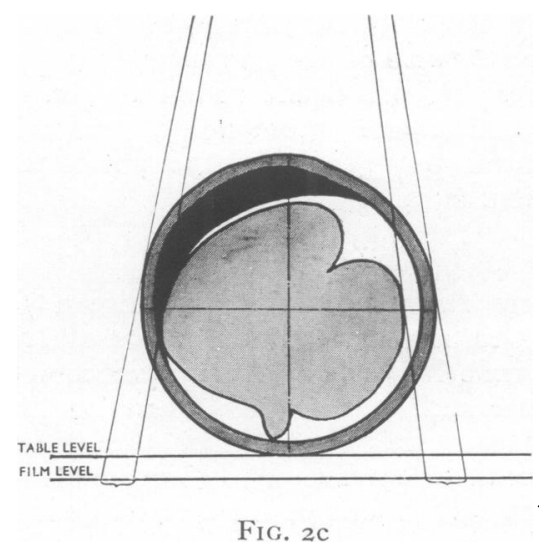

FIG. 2.-Projection of placental shadow in lateral recumbent position. (a) Symmetrical implantation on anterior or posterior wall. (b) Symmetrical implantation. Maximum depth of placenta no longer in profile to the X-ray beam owing to lateral obliquity of uterus. (c) Implantation asymmetrical and extending on to lateral wall. No " placental shadow' projected. 


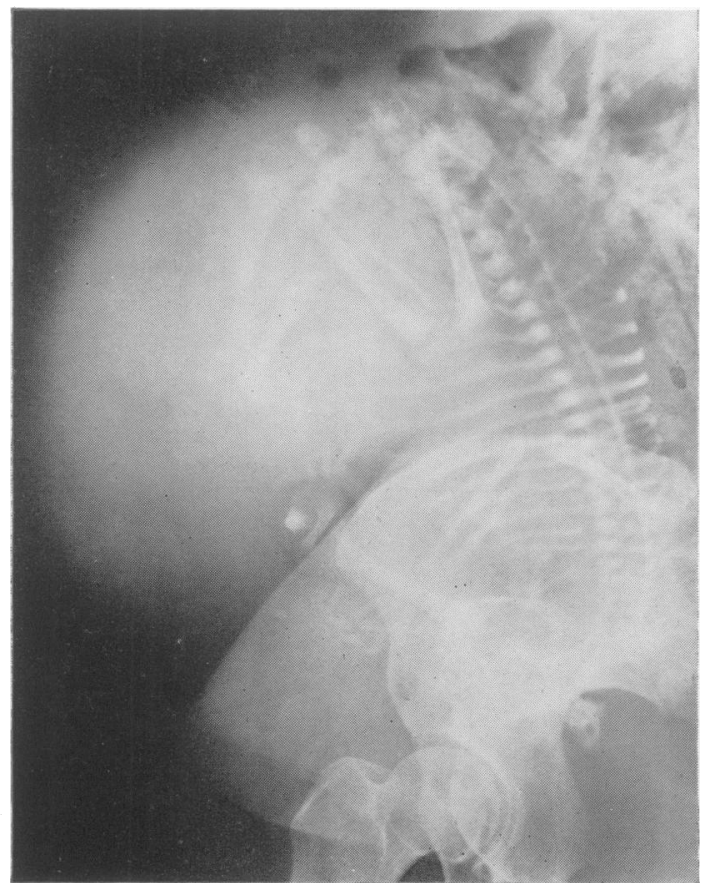

FIG. 3a.-Normal Anterior placental shadow (patient lying on her side).

plantation is anterior, and that a somewhat excessive amount of liquor lies posteriorly.

A crescentic thickening of the uterine wall which extends to the fundus does not necessarily exclude the possibility of implantation being also on the lower segment. The situation of the placenta can only be considered to be normal when films taken in erect or semi-erect positions show the presenting part within $1 \frac{1}{2} \mathrm{~cm}$. of both pubis and sacral promontory, and also in the central pelvic axis in the antero-posterior projection.

\section{(b) Lateral Implantation}

In my experience it is uncommon for the placenta to be completely on one or other lateral uterine wall. Nevertheless, on rare occasions I have suggested such a diagnosis when no placental shadow was visible on either the anterior or posterior uterine walls and low implantation could be excluded. In one of these cases, delivered by Caesarian section owing to disproportion, the placental site was, in fact, confined almost completely to one lateral wall of the upper segment.

It is also possible, on theoretical grounds, that the radiographic appearances may differ from the above description and resemble those of a normal posterior placenta. The only requirement would

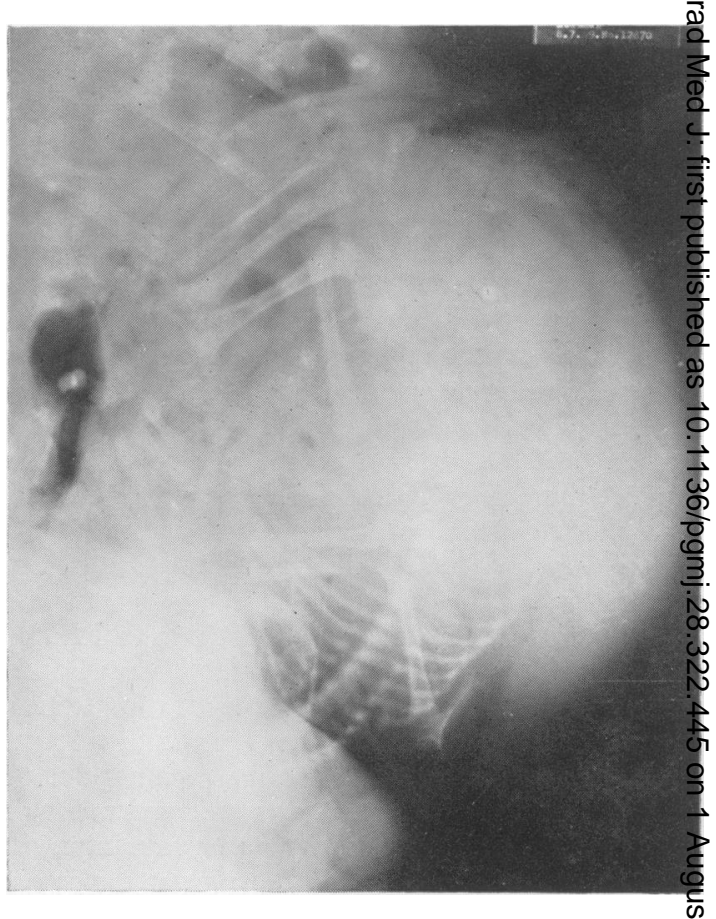

FIG. 3b.-Normal anterior placental shadow (expeet position).

be a sufficient amount of liquor amnii to form pseudo-placental shadow on the posterior uterin wall. I am not aware of any mistakes in diagnos arising in this way, but they would, in any case be of only trivial importance.

\section{The Radiological Diagnosis of Placenta Praevia}

The procedure which I adopted when working at the Radcliffe Infirmary, Oxford, is straight:forward, does not require the use of contrast media and can be performed in any department which possesses X-ray apparatus capable of producing a lateral radiograph of the pelvis in advanced pregnancy. Interpretation of the films depends on the following basic principles:

I. The actual, or potential, site of junction of the upper and lower uterine segments during thf inlet. A placenta praevia, therefore, is likely $\mathrm{t} \theta$ cause a substantial thickening of the uterine wa at the level of the brim.

2. With the foetus lying longitudinally and the mother in an upright position, the presentif part sinks downwards through the liquor un arrested in the lowest part of the uterine cavity. In normal cases, radiographs taken with the patient standing or, if necessary, reclining back wards (semi-erect) should show the presenting 
part in the central pelvic axis in the A-P view; in the lateral film it should be within a distance of the pubis and the sacral promontory, which does not greatly exceed the thickness of the intervening uterine muscle.

3. The increased depth of the uterine wall at the pelvic brim due to placenta praevia displaces the presenting part from its normal position; it may be shifted laterally to one or other side of the pelvis, backwards and upwards from the pubis, forwards from the promontory, or in more than one direction.

\section{Radiographic Technique}

In cases referred to the $\mathrm{X}$-ray department with a specific request for placental localization, films are taken as follows:

I. Lateral View of Abdomen (Erect Position). A differential filter (Reid, 1949) may be used to compensate for the widely different density of the anterior and posterior tissues, but its use is not essential. Alternatively, two exposures can be made with different degrees of penetration, or a single well-penetrated radiograph may serve if examined with variable illumination.

2. Lateral View of Pelvis (Erect Position). The patient should micturate immediately before $\mathrm{X}$-ray examination or serious fallacies in diagnosis may arise. A measuring device is usually employed for determination of diameters and distances in the sagittal plane.

3. Antero-Posterior View (Semi-Erect Position). If a tilting table is available the patient lies on her back and the head is raised about $60^{\circ}$. Exposure is made with the $\mathrm{X}$-ray tube perpendicular to the table. A similar view can be obtained on a horizontal couch by raising the patient from the supine position and supporting the shoulders at an angle of approximately 40 to $60^{\circ}$.

The object of this projection is to show any lateral displacement of the presenting part which might be due to a placenta praevia lying to one or other side of the pelvis. The semi-erect position was chosen in preference to the upright as it seemed more favourable for the presenting part to gravitate downwards along the central pelvic axis and less dependent on the state of the mothers' abdominal muscles.

The patient remains on the table until the first three radiographs have been processed. The films are inspected and, if the lateral views show a presenting part-promontory gap which measures $2 \mathrm{~cm}$. or more, a fourth radiograph is required.

4. Lateral View of Pelvis (Semi-Erect Position). In this position the presenting part should gravitate downwards and finally come to rest on the posterior uterine wall in the region of the sacral promontory. A gap which measures more than
$2 \mathrm{~cm}$. across is unlikely to be occupied by uterine muscle only and indicates a displacement of the presenting part due to placenta or to pelvic tumour.

\section{Rådiological Interpretation}

The following factors have to be considered in the X-ray diagnosis of placenta praevia:

I. The nature of the presenting part.

2. The stage of pregnancy at the time of examination.

3. The situation of the placental shadow.

I. The Presenting Part. The radiographic technique was designed to provide the most favourable conditions for gravitation of the foetus towards the pelvis in order to estimate the thickness of the uterine wall at the level of the brim. The best results are obtained in cephalic presentations; the shape of the foetal head ensures the greatest possible contact with the walls of the lower segment and, in addition, the calcified outline of the cranium is clearly visible radiographically.

When the breech is presenting there are two disadvantages compared with head presentations: in the first place, accommodation in the lower uterine pole is less accurate and, secondly, the outline of the foetal parts, a translucent band representing subcutaneous fat, is difficult ton demonstrate in the region of the pelvis.

A transverse lie is the most frequent cause of difficulty in interpretation. In some cases a wide? separation of the nearest foetal parts from the pubis or promontory, or from both, may be wholly due to placenta praevia; it is also feasible that the foetus is unable to sink into the lower pole of the uterus owing to its unfavourable situation, and that the wide soft tissue shadows lying below are mostly due to liquor amnii; a third possibility is that the gap between the presenting part and the pelvic brim contains both liquor and placenta, the transverse lie being due to the limited capacity of the lower uterine cavity resulting from low implantation.

2. The Stage of Pregnancy. X-ray examination for placenta praevia can provide useful information at any time between the 28 th and 4 oth weeks, but the significance of the radiological findings varies with the stage of pregnancy. The following is a typical example of the changes which are often found on serial radiography during the last trimester.

Mrs. W. W. was referred to the X-ray department at $3 \mathrm{I}$ weeks because of a small A.P.H. The radiographs showed a vertex presentation, the head being $1.0 \mathrm{~cm}$. above the pubis; in the semi-erect position it was $4.1 \mathrm{~cm}$. from the promontory and displaced slightly to the right. As the placental shadow was posterior, these findings indicated extension downwards over the promontory on to 
the posterior and left lateral walls of the lower segment. The radiological diagnosis was low posterior implantation and probably placenta praevia. At 36 weeks the presentation had not altered; the head-pubis distance was $1.3 \mathrm{~cm}$., the head promonotory gap was now $3.6 \mathrm{~cm}$. and there was no longer any doubt about the diagnosis of placenta praevia. Further confirmation was obtained at $37 \frac{1}{2}$ weeks when the head was $\mathrm{I} \mathrm{cm}$. from the pubis and $3.2 \mathrm{~cm}$. from the sacral promontory. A few days later, Mr. Stallworthy performed Caesarean section and found the placenta situated posteriorly, extending downwards to the edge of the internal os and also slightly on to the left lateral wall of the lower segment.

In the above and similar cases the diminishing displacement of the presenting part can be explained by expansion of the lower segment and continuing growth of the uterus; in consequence there is a decreasing depth of placenta at the brim due to the upward movement of its pelvic extension.

In other patients, the presenting part is found to be displaced on first examination, but normally situated in radiographs taken a few weeks later. Although the later findings show the placenta entirely in the abdomen, its lower margin may have been below the pelvic brim when the first $\mathrm{X}$-rays were taken. In these cases it is impossible to say whether implantation is normal but unusually low, or extending slightly on to the lower segment; further differentiation would require precise knowledge of the site of junction of the uterine segments.

\section{The X-Ray Diagnosis of Placenta Praevia}

The factors involved are so variable that no hard and fast rules can be laid down. Nevertheless, information can be obtained in most cases which is reliable, sufficiently accurate to be useful to the obstetrician and without risk to either mother or baby. During the last five years I have made a detailed analysis of the X-ray findings in well over 700 patients (Reid, 1949 and 195I) in the light of their subsequent clinical histories. The method of radiographic interpretation which is outlined below is based on the experience acquired in these cases. It should not be applied too rigidly but used rather as a guide, each particular case being considered on its own merits.

Lateral radiographs show the presenting part within $\mathrm{I} \frac{1}{2} \mathrm{~cm}$. of both pubis and promontory.

(a) Transverse Lie. Placenta praevia can be excluded.

(b) Breech or Head Presentations. Placenta praevia can be excluded, provided the A.P. view shows the presenting part lying in the centrat pelvic axis.

The placental shadow is continuous with a soft tissue space separating the presenting part from either the pubis or the promontory which measures $1 \frac{1}{2}$ to $2 \mathrm{~cm}$.

(a) Transverse Lie. Placenta praevia can be excluded.

(b) Breech or Head Presentations.

Twenty-eight to thirty-four weeks.-Placentæ praevia can be excluded if there is no lateral displacement of the presenting part.

Thirty-four to forty weeks. - Unless the patient has been X-rayed at an earlier stage of pregnance re-examination is advisable within one to two weeks. Placenta praevia can then be exclude $\bar{\Phi}$. if the soft tissue gap is less than $1 \frac{1}{2} \mathrm{~cm}$. and theres is no lateral shift of the presenting part. Nou appreciable change in the width of the soft tissus space is suspicious of placenta extending down wards to the brim, but any significant degree of implantation on the lower segment is unlikely unless there is also some lateral displacement. If similar, or wider, displacement was present an earlier stage of pregnancy, the findings indicate a minor degree of placenta praevia.

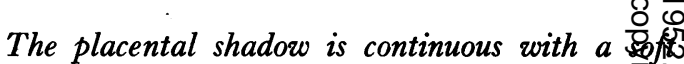
tissue space separating the presenting part foint either the pubis or the promontory and the dept ${ }^{+}+{ }^{2}$ which measures more than $2 \mathrm{~cm}$.

(a) Transverse Lie.

Twenty-eight to thirty-four weeks.-A sofo tissue gap measuring 2 to $3 \mathrm{~cm}$. is unlikely to be of any significance. A distance of 3 to $4 \mathrm{~cm}$. is probably due to low normal implantation or minor degree of placenta praevia. If the space measures more than $4 \mathrm{~cm}$. the possibility of a majox degree of placenta praevia has to be considered

Unless a radiological opinion is urgent $/ \bar{\not}$. required it is usually advisable to temporize anç if the obstetrician is willing to co-operate, awais further X-rays after version. The head or breec is often found to be presenting when the patien\$ arrives for re-examination; if not, version at tempted may be preferably in or near the radiology department so that films can be exposed with the least possible delay in case the malpresentatiog should recur.

Thirty-four to forty weeks.-Placenta praevi⿺廴⿱ can be excluded if the displacement is less that $2 \frac{1}{2} \mathrm{~cm}$. and a major degree of the condition neeg not be considered unless the distance exceeds $3 \mathrm{~cm}$

(b) Breech or Head Presentations.

Twenty-eight to thirty-four weeks. - A tentative diagnosis of ' low lying' placenta can be madeo The likelihood of placenta praevia increases wit 
BEFORE MICTURITION

LATERAL PELVIS ERECT POSITION

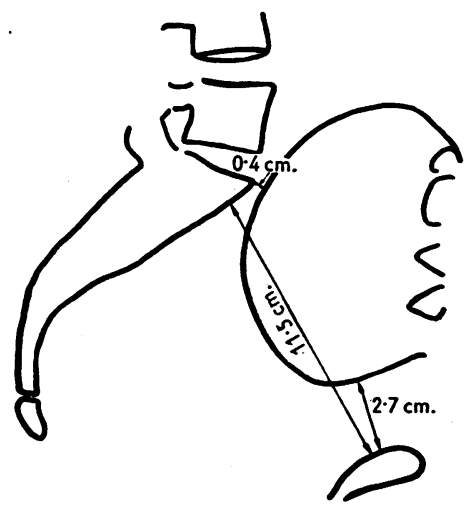

LATERAL PELVIS. AFTER MICTURITION ERECT POSITION

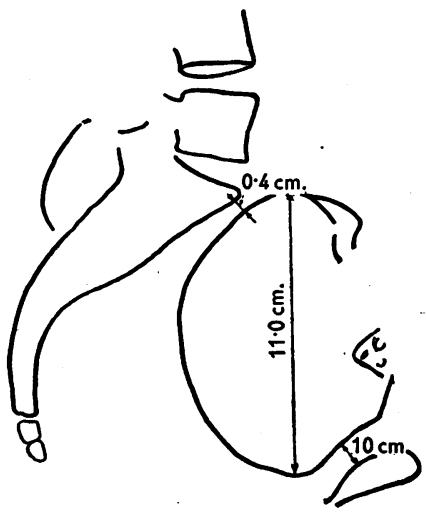

Fig. 4.-Upward displacement of foetal head due to full bladder.

the degree of displacement; in addition a given displacement from pubis or promontory is more convincing evidence when the presenting part is also displaced laterally.

If the pregnancy continues, further $\mathrm{X}$-rays should be obtained after an interval of two, three or four weeks and, where time allows, a third. examination is often useful. When the radiographic appearances are normal at the second, or later, investigation, placenta praevia can be excluded; persistent displacement of the presenting part shows some degree of implantation on the lower segment.

Thirty-four to forty weeks.-Placenta praevia is indicated when a similar or greater displacement was present at an earlier stage of pregnancy. In cases not examined previously further $\mathrm{X}$-rays may be useful after a relatively short interval of one to two weeks; if these show little or no change a more confident diagnosis of placenta praevia can be made.

The amount of displacement of the presenting part is not always in proportion to the type of placenta praevia, but radiologically it is usually possible to differentiate between a minor or a major degree. For example, if the head or breech is $4 \mathrm{~cm}$. or more from the pubis or promontory and, in addition, some $2 \mathrm{~cm}$. or more to one side of the central pelvic axis, then the placenta is almost certainly extending well down into the pelvic cavity, with its lower margin in the neighbourhood of, or completely covering, the internal os. On the other hand, when the anterior or posterior displacement of the presenting part does not greatly exceed $2 \mathrm{~cm}$. and there is no associated lateral shift, there is unlikely to be more than a minor degree of extension on to the lower segment.

\section{Differential Diagnosis \\ Full Bladder (Fig. 4)}

It is a wise precaution to make a routine request of all patients to empty the bladder immediately before X-ray examination. On several occasions I have found appearances of anterior placenta praevia in patients who had not recently passed urine; further lateral films, taken immediately after micturition, showed a normal distance from the pubis to the presenting part and thereby excluded any question of placenta praevia. In none of these cases did the bladder seem to be distended and the two or three ounces of urine usually voided was enough to restore the radiographic appearances to normal.

\section{Loaded Bowel}

An accumulation of faeces in the pelvis is easy to recognize in a good lateral radiograph and is a fairly common finding in late pregnancy. Although well known clinically as a cause of nonengagement, it is only rarely that a loaded bowel is found to be responsible for displacing the presenting part from the pelvic brim. Nevertheless, the possibility must be considered when the radiographs show displacement from the sacral promontory, a posterior placental shadow and a mass of faeces in the pelvic colon or the rectum. In these circumstances, diagnosis should be postponed and the patient re-examined after defaecation or, if necessary, following an enema; persistence of the presenting part displacement shows the presence of a posterior placenta praevia and indicates that the loaded bowel in the earlier films was merely an incidental finding.

In other cases the placental shadow is anterior and the presenting part displaced from the pro- 
montory but in normal relationship to the remainder of the pelvic brim. Although here a loaded rectum is the most likely cause of displacement and placenta praevia can be excluded, it is, nevertheless, advisable to re-examine the patient after defaecation. Little or no change in the presenting part-promontory distance indicates a tumour in the posterior part of the pelvis.

\section{Pelvic Tumours}

Radiographs of the pelvis in pregnancy occasionally reveal appearances typical of a bone neoplasm, a calcified fibroid or a dermoid cyst. But the radiographic density of most tumours is identical with that of uterine muscle, placenta or other neighbouring soft tissues and radiological diagnosis is only possible when the mass is large enough to displace the presenting part from its normal relationship to the pelvic inlet. Differentiation from placenta praevia may be difficult, but is sometimes possible when there is no radiographic evidence of continuity between the placental shadow and the soft tissue space at the site of the presenting part displacement.

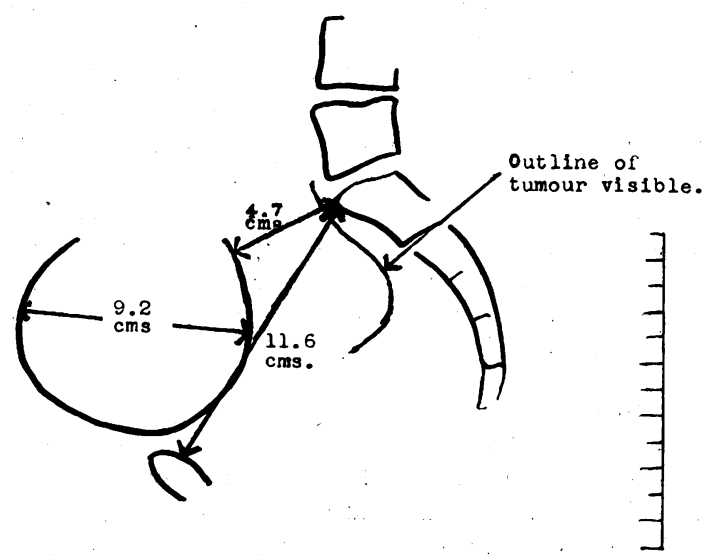

FIg. 5a.-J.C. Posterior pelvic tumour. Lateral view of pelvis (semi-erect position).

In Fig. 5, for example, the foetal head was displaced $4.7 \mathrm{~cm}$. forwards from the promontory; the placental shadow was anterior, but the normal relationship of the head to the pubis and lateral margins of the brim excluded any possibility of extension downwards into the pelvis. No further evidence was required for the diagnosis of a tumour, but in this particular case the rounded outline of a soft tissue mass was visible in front of the sacrum by virtue of the gas contained in the pelvic colon and rectum. My diagnosis of a tumour in the posterior part of the pelvis was verified at Caesarean section when a fibroid the size of an orange was found on the posterior uterine wall below the sacral promontory.

Radiographic appearances resembling those in the case described above are conclusive with $\overrightarrow{\text { ar }}$ without the demonstration of the tumour itseff, but differential diagnosis from placenta praeva is impossible when the placental shadow is co항 tinuous with the soft tissue gap which separatess the presenting part from the brim. Even if the outline of a tumour is visible in the pelvis, the possibility of displacement being due, partly wholly, to placenta praevia cannot be excluded. $\overrightarrow{\vec{H}}$

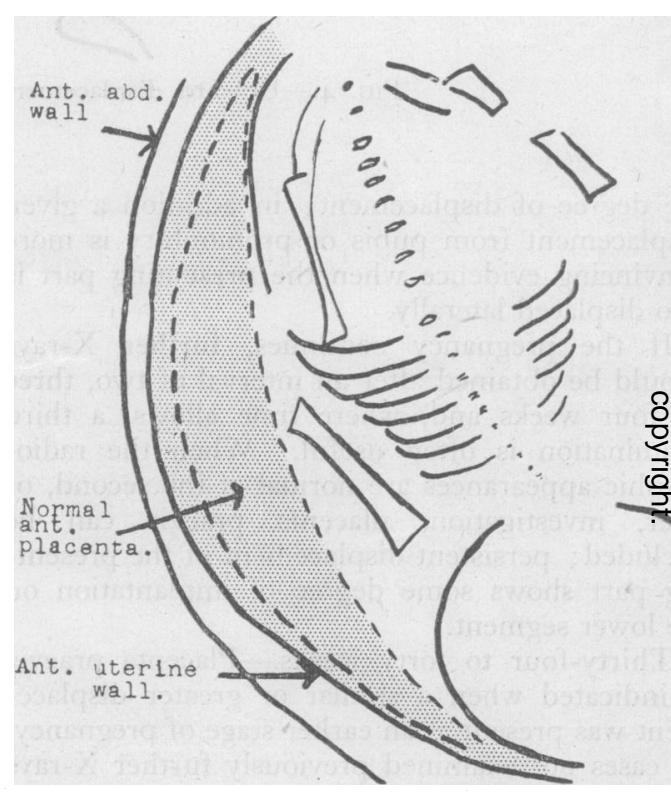

Fig. 5b.-J.C. Lateral abdomen (erect). Anterior placental shadow not extending into pelvis.

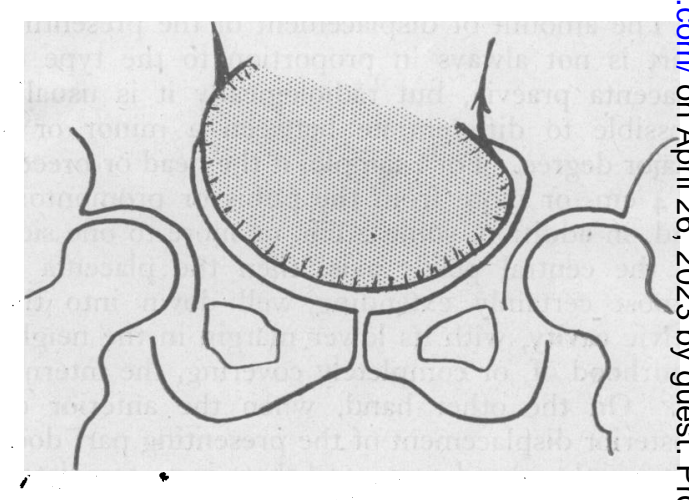

Fig. 5c.-J.C. Antero-posterior view of pelvis (ser⿸户 erect). Foetal head in normal situation. 


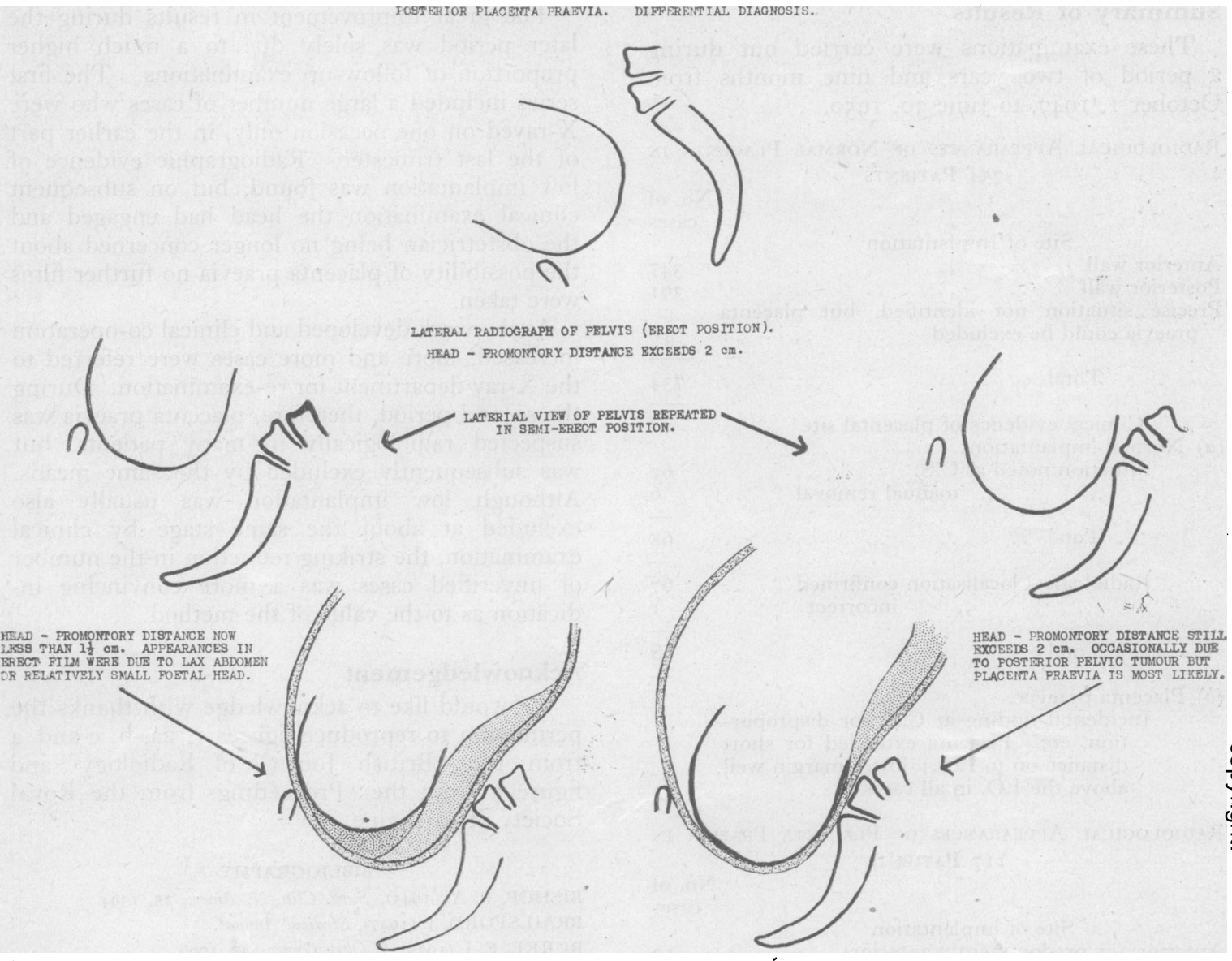

\section{Lax Abdominal Muscles}

In the upright position the foetus gravitates downwards and, in normal cases, backwards in the direction of the pelvic inlet. But when the tone of the abdominal muscles is impaired, there is a tendency for the presenting part to drop directly down and become arrested either immediately above the pubis or, in extreme cases, further forwards where a pouch is formed by the sagging abdominal wall. Nevertheless, a lax abdomen should not be accepted too readily as the cause of a presenting part which lies too far forward; it is important to remember that the abnormal situation of the foetus may be due to placenta praevia or a pelvic tumour, and that the impaired abdominal musculature may be merely incidental. To differentiate, further films should be taken in the semi-erect position; provided these show the presenting part within one or two centimetres of the promontory and also equidistant from the lateral margins of the inlet, placenta praevia and tumour can be excluded.

\section{The Early Diagnosis of Placenta Praevia}

The displacement method causes the patient less disturbance, and has proved more successful than procedures which involve the use of contrast media. A further advantage is derived from the simple nature of the radiographic technique employed. By including the erect lateral radiograph - diagnostic in over 95 per cent. of cases-as an integral part of all X-ray examinations in pregnancy, placenta praevia is sometimes revealed before the onset of haemorrhage.

A recent series of 32 clinically confirmed cases of placenta praevia included 17 patients who had been examined radiologically because of a previous A.P.H. Although the remaining 15 gave no history of A.P.H., some were referred for X-ray examination because placenta praevia was suspected clinically, the others being sent for routine investigation of non-engagement, transverse lie, etc. The 15 patients examined and diagnosed radiologically before the onset of haemorrhage included four cases of central placenta praevia and seven of Type I. 


\section{Summary of Results}

These examinations were carried out during a period of two years and nine months from October I, I947, to June 30, 1950.

Radiological Appearances of Normal Placenta in 754 Patients

No. of cases

$\begin{array}{lllllll}\text { Anterior wall } & \ldots & \ldots & \ldots & \ldots & \ldots & 347\end{array}$

Posterior wall
Precise situation not identified, but placenta praevia could be excluded $\quad \ldots \quad \ldots . \quad \ldots \quad 16$

$\begin{array}{lllllll}\text { Total } & . & \ldots & \ldots & \ldots & \ldots & 754\end{array}$

Clinical evidence of placental site

(a) Normal implantation:

Situation noted at C.S. $\ldots \quad \ldots \quad \ldots \quad \ldots 6$ , ," , manual removal $\quad \ldots \quad 6$

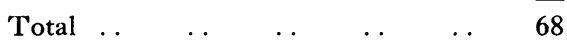

Radiological localisation confirmed $\quad \ldots \quad \overline{67}$ ,", incorrect $\quad . \quad 1$

$\begin{array}{lllllll}\text { Total } & \ldots & \ldots & \ldots & \ldots & \ldots & 68\end{array}$

(b) Placenta praevia:

Incidental finding at C.S. for disproportion, etc. Placenta extended for short distance on to L.S.; lower margin well above the I.O. in all cases

Radiological Appearances of Placenta Praevia in I 7 Patients

No. of cases

Site of implantation

Anterior (or predominantly anterior) . . . 53 Posterior (, , , , ) . $\quad \ldots .64$

$\begin{array}{lllllll}\text { Total } & \ldots & \ldots & \ldots & \ldots & \ldots & 117\end{array}$

Clinical evidence of placental site

(The $I 17$ cases consists of two series investigated during successive periods of 15 and 18 months (Reid, 1949 and 195I). Comparison of the results obtained is instructive)

\begin{tabular}{|c|c|c|}
\hline & \begin{tabular}{|c|} 
Ist series \\
Examined \\
between \\
1.10.47- \\
31.12 .48 \\
(1 5 mths.)
\end{tabular} & $\begin{array}{l}\text { 2nd series } \\
\text { Examined } \\
\text { between } \\
\text { 1.1.49- } \\
30.6 .50 \\
\text { (18 mths.) }\end{array}$ \\
\hline $\begin{array}{l}\text { X-ray appearances of placenta } \\
\text { praevia } \ldots \\
\text { Complete clinical proof ob- } \\
\text { tained at C.S. or palpation } \\
\text { p.v. } \\
\text { Unreliable evidence of pla- } \\
\text { centa praevia from inspec- } \\
\text { tion after delivery, etc. } \\
\text { No clinical evidence of pla- } \\
\text { centa praevia at delivery .. }\end{array}$ & $\begin{array}{c}\text { No. of cases } \\
73 \\
22\end{array}$ & $\begin{array}{c}\text { No. of cases } \\
44\end{array}$ \\
\hline \begin{tabular}{ccc}
$\begin{array}{c}\text { Proportion of } \\
\text { proved cases }\end{array}$ & \multicolumn{2}{c}{ proved/un- } \\
\end{tabular} & $30 \%$ & $73 \%$ \\
\hline
\end{tabular}

The great improvement in results during the later period was solely due to a much high proportion of follow-up examinations. The first series included a large number of cases who were $\mathrm{X}$-rayed on one occasion only, in the earlier pa्Ft of the last trimester. Radiographic evidence $\vec{\theta} f$ low implantation was found, but on subsequeft clinical examination the head had engaged and the obstetrician being no longer concerned abowit the possibility of placenta praevia no further films were taken.

As the work developed and clinical co-operation increased, more and more cases were referred to the X-ray department for ree-examination. Duris the second period, therefore, placenta praevia was suspected radiologically in many patients, but was subsequently excluded by the same means. Although low implantation was usually alog excluded at about the same stage by clinigol examination, the striking reduction in the numbir of unverified cases was a more convincing i dication as to the value of the method.

\section{Acknowledgement}

We would like to acknowledge with thanks permission to reproduce figures $\mathrm{I}, 2 \mathrm{2}, \mathrm{b}, \mathrm{c}$ and ${ }^{\mathrm{m}}+4$ from the 'British Journal of Radiology' $\beta_{a} \vec{d}$ figure 7 from the 'Proceedings from the Society of Medicine.

\section{BIBLIOGRAPHY}

BISHOP, P. A. 1945), Surg. Clin. N. Amer., 25, 394. BRAILSFORD, J. (1947), Medical Annual. BURKE, F. J. (1935), 7. Obst. Gynec., 42, 1096.

BUXTON, B. H., HUNT, R. R., and POTTER, C. (1942), An⿳⺈⿴囗十灬r. F. Roentg., 43, 610.

DIPPEL, A. L., and BROWN, W. H. (1940), Amer. F. Obst. Gy 50, 986.

DIPPEL, A. L., and BROWN, W. H. (1946), Bull. fohns Hopk. Hosp., 46, 9o.

EHRHARDT, K. (1932), Klin. Wschr., II, 332.

EHRHARDT, K. (1939), Zbl. Gynak., 43, 2335.

GOLDEN, R., and BALL, B. P. (1941), Amer. F. Obst. Gyn.,,$\underset{6}{3}$, 530.

KATSUYA, S. (1932), fap. F. Obst. Gyn., 15, 77.

KERR, J. M. M., and MCKAY, W. G. (1933), Trans. Edin. Soc., 21.

LLOYD, O., and SAMUEL, E. (194I), f. Obst. Gyn., 48, D

MENEES, T. O., MILLER, J. D., and HOLLY, L. E. (19 Amer. F. Roentg., 24, 363.

OLSSON, O. (194I), Acta Radiol., 129.

REID, F. (1949), Brit. F. Radiol., 22, 254; 22, 262.

REID, F. (I95 I), Proc. Roy. Soc. Med., 44, 703.

SANTE, L. R. (195I), Radiology, 56, 183.

SMITH, R. MANGES (1943), Amer. F. Roentg., 37, 49.

SNOW, W., and POWELL, C. B. (1934), Ibid., 31, 37.

STANDER, H. J. (1942), Amer. F. Obt. Gyn., 44, 53 I.

SOHRNE, G. (1942), Acta Radiol. Stockh., 23, 6, 54 r.

UDE, W. H., WEUM, T. W., and URNER, J. A. (1934), Ұ. Rientg., 3I, 230. 